\title{
Inventarisasi Data Pengetahuan (Ontologi) Dalam Upaya Penyusunan Kompendium Keilmuan Komunikasi Hindu Berbasis Budaya
}

\author{
Ni Gusti Ayu Ketut Kurniasari ${ }^{1}$, I Wayan Budha ${ }^{2}$, Untung Suhardi ${ }^{3}$, Anak Agung \\ Ketut Patera $^{4}$, I Wayan Arif Sugiarta ${ }^{5}$, Wayan Tantre Awiyane ${ }^{6}$ \\ ${ }^{123456}$ Sekolah Tinggi Agama Hindu Dharma Nusantara Jakarta \\ 1jegegyuke@gmail.com, ${ }^{2}$ budhawayan4@gmail.com, ${ }^{3}$ untungsuhardi18@gmail.com, \\ 4agungpatera@gmail.com, ${ }^{5}$ wynarif@gmail.com, ${ }^{6}$ wayantantre96@gmail.com
}

\begin{abstract}
Industrial development 4.0 and 5.0 who moved so fast bring curriculum changes in policy direction. However, of the curriculum change independent learning independent campus bring their own special characteristics culture, on the local wisdom and digitalisasi. The theory used in this research was vakyapadia, rasa theory and theory of computer mediated communication. Using paradigm critical and methods of using vakyapadiya linguistic analysis, data collection through study library and forum groub discussion. Research findings curriculum is based design culture culture; existence as a basis for curriculum design, the vedas as philosophical curriculum design, harmonisation as a purpose in the design, curriculum and Brahman as a source of knowledge and object characteristic hindu communication. In addition, cultural values and the philosophical hindu became the basis in the design independent curriculum learning campus independent and be the reference in the vedas philosophical developed the theory hindu communication based scientific culture.
\end{abstract}

Keyword: Curriculum; The Science Of Communication; Hindu; Culture

\begin{abstract}
Absbtrak
Perkembangan Industri 4.0 dan 5.0 yang bergerak begitu cepat membawa perubahan pada arah kebijakan kurikulum. Namun demikian, perubahan kurikulum merdeka belajar kampus merdeka membawa karakteristik tersendiri pada aspek budaya, kearifan lokal dan digitalisasi. Dalam penelitian ini menggunakan teori Vakyapadia, model komunikasi Hindu Sadharanikaran, Teori Rasa dan Teori Computer Mediated Communication. Penelitian ini menggunakan paradigma kritis serta metode analisis linguistik Vakyapadiya. Teknik pengumpulan data melalui studi pustaka dan Forum Group Diskusi. Hasil penelitian adalah perancangan kurikulum MBKM Ilmu Komunikasi Hindu berbasis Budaya; eksistensi budaya sebagai dasar dalam perancangan kurikulum MBKM Ilmu Komunikasi Hindu, Weda sebagai filosofis perancangan kurikulum MBKM di Prodi Ilmu Komunikasi Hindu, harmonisasi sebagai tujuan dalam perancangan kurikulum MBKM Ilmu Komunikasi Hindu, dan Brahman sebagai sumber dan objek karakteristik Ilmu Komunikasi Hindu. Selain itu, Nilai-nilai Hindu dan nilai-nilai budaya menjadi dasar filosofis dalam perancangan kurikulum Merdeka Belajar Kampus Merdeka dan Weda menjadi rujukan filosofis dalam mengembangkan kompedium keilmuan komunikasi Hindu berbasis budaya.
\end{abstract}

Kata Kunci: Kurikulum; Ilmu Komunikasi; Hindu; Budaya. 


\section{Pendahuluan}

Perkembangan pendidikan di Indonesia sangat terkait dengan adanya perkembangan teknologi dan komunikasi di era globalisasi yang melanda seluruh dunia pada abad ke 21, sehingga menyebabkan tujuan pendidikan nasional tidak lagi hanya untuk mencerdaskan bangsa dan memerdekakan manusia namun bergeser mengarah kepada pendidikan sebagai komoditas karena lebih menekankan penguasaan Ilmu Pengetahuan, Teknologi, dan Seni (IPTEKS) yang bersifat pragmatis dan materialis (Suwandi, 2020). Dalam proses pendidikan, salah satu komponen penting adalah kurikulum yang merupakan suatu program pembelajaran sehingga diperlukan adanya rancangan, pelaksanaan serta evaluasi yang disesuaikan dengan perkembangan zaman, dan kebutuhan Ilmu Pengetahuan, Teknologi, dan Seni (IPTEKS) serta kompetensi yang dibutuhkan oleh masyarakat, maupun pengguna lulusan perguruan tinggi. Perkembangan IPTEKS di abad ke-21 yang berlangsung secara cepat mengikuti pola logaritma, menyebabkan Standar Pendidikan Tinggi (SN-Dikti) juga mengikuti perubahan tersebut (Penyusun, 2020).

Pengemasan kurikulum sangat mempertimbangkan hak dan kewajiban masingmasing perguruan tinggi, namun juga harus berlandaskan pada UUD 1945, UU No. 12 Tahun 2012, Standar Nasional Pendidikan Tinggi yang dituangkan dalam 4 Direktorat Jenderal Pendidikan Tinggi Permendikbud No. 3 Tahun 2020, serta ketentuan lain yang berlaku. Pada dasarnya, kurikulum harus mampu membuat mahasiswa menguasai ilmu pengetahuan dan membentuk mahasiswa memiliki keterampilan tertentu dan memiliki dasar budi pekerti luhur, sehingga mahasiswa akan mampu berkontribusi dalam menjaga nilai-nilai kebangsaan, kebhinekaan, mendorong semangat kepedulian kepada sesama bangsa dan umat manusia untuk meningkatkan kesejahteraan sosial yang berkeadilan serta kejayaan bangsa Indonesia. Secara garis besar kurikulum, sebagai sebuah rancangan, terdiri dari empat unsur, yakni capaian pembelajaran, bahan kajian yang harus dikuasai, strategi pembelajaran untuk mencapai, dan sistem penilaian ketercapaiannya (Junaedi, 2020:12).

Nilai-nilai Veda menjelaskan bahwa seseorang yang memberikan pendidikan disebut àcàrya. Nama lainnya adalah "adhyàpaka" yang juga berarti guru, di samping kata "guru" itu sendiri, sedang siswa (perubahan dari kata sisya) disebut Brahmacàri, juga disebut "vidyàrti", yang berarti yang mengejar dan mempelajari ilmu pengetahuan. Àcàrya berarti seseorang yang dianggap tidak hanya memberikan ilmu pengetahuannya secara teoritis kepada para siswa, tetapi juga memperbaiki karakter mereka. Pengertian àcàrya adalah: "àcàraý grahayatìti àcàryaá" yang berarti ia yang memberikan pendidikan karakter (seseorang). Dua hal penting dalam sistem pendidikan menurut Veda adalah brahmacarya dan àcàrya dan melalui kebersamaan keduanya seorang siswa dapat meningkatkan perbaikan moralitas dan karakternya (Titib, 1997). Adalah tugas seorang guru, ketika seorang siswa menghadapnya, untuk meminta diajarkan kepadanya tentang kebenaran yang sesungguhnya yang ia ketahui (Mundaka Upaniśad I.2.13), tanpa menyembunyikan sesuatu dari padanya, untuk sesuatu yang disembunyikan akan mengakibatkan kejatuhannya (Praśna Upaniśad VI.1). Kitab Taittirìya Àraṅyaka (VII.4) menguraikan bahwa seorang guru mestinya mengajar siswanya dengan sepenuh hati dan jiwanya. Ia juga terikat, yang menurut Śatapatha Bràhmana (XIV.I.1.26.27) untuk menguraikan segala sesuatunya kepada para siswa, yang tinggal selama setahun penuh (saývatsara-vàsin) (Sudiani, 2020).

Proses pembelajaran dalam Kampus Merdeka merupakan salah satu perwujudan pembelajaran yang berpusat pada mahasiswa (student centered learning) yang sangat esensial (Baharuddin, 2021). Pembelajaran dalam Kampus Merdeka memberikan tantangan dan kesempatan untuk pengembangan kreativitas, kapasitas, kepribadian, dan kebutuhan mahasiswa, serta mengembangkan kemandirian dalam mencari dan 
menemukan pengetahuan melalui kenyataan dan dinamika lapangan seperti persyaratan kemampuan, permasalahan ril, interaksi sosial, kolaborasi, manajemen diri, tuntutan kinerja, target dan pencapaiannya (Suryaman, 2020). Melalui Merdeka Belajar - Kampus Merdeka diharapkan dapat menjawab tantangan Perguruan Tinggi untuk menghasilkan lulusan sesuai perkembangan IPTEK dan tuntutan dunia usaha dan dunia industri. Proses penyusunan dan pengembangan kurikulum merdeka belajar pada tataran implementasi akan tergambar Proses Penyusunan Dan Pengembangan Kurikulum Merdeka Belajar

Pemikiran tentang kondisi ideal yang tertuang dalam pedoman penyusunan kurikulum Merdeka Belajar Kampus Merdeka masih menyisakan permasalahan tersendiri mulai dari: 1) Dasar regulasi Ditjen Bimas Hindu, 2) Kesiapan Perguruan Tinggi Keagamaan Hindu penyelenggara Prodi Ilmu Komunikasi Hindu, 3) Sumber Daya Manusia, 4) Kurikulum Penciri berdasarkan kekhasan wilayah, 5) Implementasi MBKM, dan 6) Luaran Lulusan. Serangkaian problematika yang terjadi ini merupakan permasalahan yang sangat serius untuk diselesaikan karena untuk masa depan lembaga dan lulusan nantinya. Namun demikian, rancangan kurikulum yang dilaksanakan ini merupakan bagian yang tidak dapat untuk ditinggalkan dengan adanya kekhasan yang dimiliki oleh STAH DN Jakarta. Untuk itu, pendalaman yang nantinya akan menjadi perbaikan kurikulum adalah nilai filosofis dai Veda tidak dapat untuk ditinggalkan dan bingkai kearifan lokal juga tidak dapat ditinggalkan. Dengan demikian, penyusunan kurikulum MBKM Prodi Komunikasi Hindu ini mendasarkan pada paradigma Veda, Keilmuan yang saat ini berkembang dan juga budaya serta kearifan lokal yang harus dilestarikan. Dengan demikian penelitian ini fokus pada Rancangan Kurikulum Ilmu Komunikasi Hindu MBKM Berbasis Budaya.

\section{Metode}

Penelitian ini menggunakan Paradigma Kritis (Salim, 2001). Dimana paradigma kritis menfokuskan pada esensi realitas sosial dengan mempersoalkan ketimpangan relasi sosial yang terjadi. Metode analisis linguistik yang menjadi dasar dalam pemahaman Vakyapadiya (Pillai, 1971). Dimana dalam analisis linguistik Vakyapadiya setiap kata memiliki rasa sebagai sumber dan objek sang Brahman. Sebagai subyek dalam penelitian ini adalah ahli budaya, ahli digital, perwakilan masyarakat, dan pemuka agama serta stakeholder dari prodi ilmu komunikasi Hindu. Metode pengumpulan data yang dilakukan adalah dengan wawancara, studi pustaka dan dokumentasi, serta FGD telah dilaksanakan pada tanggal 4 November 2021, via zoom Meeting dengan jumlah peserta sebanyak 61 orang.

Analisis data kualitatif bersifat induktif, yaitu analisis berdasarkan data yang diperoleh. Menurut Miles \& Huberman (Sugiyono, 2006) analisis terdiri dari tiga alur kegiatan yang terjadi secara bersamaan yaitu: reduksi data dimana peneliti melakukan reduksi melalui tiga tahap yaitu pre coding, coding dan pemaknaan, selanjutnya peneliti melakukan penyajian data dengan memaparkan temuantemuan yang telah dihasilkan, dan untuk yang terakhir peneliti melakukan penarikan kesimpulan/verifikasi yang dikemas dalam bagan hasil penelitian.

\section{Hasil dan Pembahasan}

\section{Eksistensi Budaya}

Menjaga eksistensi budaya adalah suatu kewajiban dari sebuah lembaga pendidikan. Hal tersebut dapat tercantum secara detail dalam perancangan kurikulum yang akan dikaji. Seperti pernyataan salah satu narasumber dalam focus group discussion yang dilaksanakan pada tanggal 4 November 2021 yaitu Dr. Ahmad Toni, M.I.Kom yang 
menjelaskan secara detail bahwa, perlu adanya keberanian dan komitmen yang kuat sebagai lembaga pendidikan untuk terus tetap melesatarikan budaya sebelum budaya tersebut hilang dan tergerus oleh srus globalisasi. Seperti pernyataan berikut ini: Kajian kritis, mengapa budaya sendiri dibatasi, semestinya diberikan kebebasan yang luas. Jika budaya dibatasi maka budaya itu tidak akan berkembang justru naasnya akan menjadi punah atau hilang karena tidak ada yang melestarikan.

Hal menarik juga disampaikan oleh I Gusti Made Arya Suta Wirawan, S.Hum., M.Si dalam focus group discussion yang dilaksanakan pada tanggal 4 November 2021, yang memaparkan bagaimana upaya membangun eksistensi budaya Hindu sudah dilakukan sejak jaman dahulu kala. Dimana penekanan nilai-nilai Hindu tumbuh abadi dalam setiap budaya yang berkembang di seluruh dunia. Walau dalam perkembangannya, tentu saja mengalami berbagai rintangan dan kendala yang mengusik esistensi dari keberadaan budaya Hindu itu sendiri. Seperti pada pernyataan berikut:

Pada prinsipnya adalah tentang bagaimana problem komunikasi itu muncul ketika Hindu menyebarluaskan dirinya keberbagai penjuru dunia. Nilai Hindu yang cinta kasih membuat agar budaya yang adi luhung bersintesa dengan ajaran-ajaran dharma. Hindu sebenarnya muncul diberbagi belahan dunia, hanya saja ilmuwan barat mengkonstruksi tidak hanya sejarah peradaban namun juga Wedanya. Muncul satu hipotesa bahwa Hindu menyebar diberbagai belahan dunia.

Demikian juga yang disampaikan oleh Informan selanjutnya yaitu Dewa Ketut Suratnaya, S.Ag., M.M.Pd dalam focus group discussion yang dilaksanakan pada tanggal 4 November 2021, yang menjelaskan perkembangan budaya nusantara hingga masuknya Hindu ke Indonesia. Yang menarik dalam penjelasan tersebut juga menekankan bahwa komunikasi memiliki peran penting dalam proses penyebaran agama Hindu ke nusantara serta berbaur dalam budaya-budaya di Indonesia yang salah satunya adalah budaya Bali. Ini menjadi penekanan yang baik, karena budaya bali yang merupakan salah satu budaya di Indonesia menjadi saksi sejarah bagaimana perjuangan Hindu masuk ke Indonesia menghadapi begitu banyak kendala dan rintangan. Dalam pejelasan ini juga menjelaskan bahwa bagaimana pentingnya membangun pemahaman budaya sedari dini dan mengimplementasikannnya dalam kehidupan sehari-hari sehingga budaya dan nilai-nilai Hindu terus terjaga dengan baik. Seperti penjelasan berikut ini:

Kelemahan kita memang komunikasi, komunikasi menjadi tangga ketika berbicara tentang literasi. Memang dari sejarah 200 SM-700 M. Masuk Hindu ke Indonesia. Mengalami penjajahan yang sangat lama. Namun kemudian Hindu di Indonesia mampu berkembang. Ada waktu Hindu disempurnakan di Bali. Agama Hindu dipelajari di lapangan. Komunikasi tidak hanya bersifat duniawi namun juga bersifat non duniawi. Perlu dilaksanakan secara praktik tentang metode pengenalan Hindu sejak dini.

Eksistensi budaya menjadi salah satu dasari penting dalam perancangan kurikulum MBKM Prodi Ilmu Komunikasi Hindu. Namum sebagai dasar filosofis dari perancangan kurikulum adalah Weda. Weda menjadi rujukan yang sahih dan sangat komprehensif dalam menjelaskan semua komponen kehidupan baik secara skala dan niskala. Weda dirancang dengan sangat detail dan rijit sebagai rujukan dan dasar filosofis dalam perancangan kurikulum MBKM di Prodi Ilmu Komunikasi Hindu. Lebih lanjut, terkait dengan eksistensi budaya dalam perkembangan nilai-nilai Hindu harus menjadi dasar yang kuat dalam perancangan kurikulum di Program Studi Ilmu Komunikasi Hindu. Dimana komunikasi sebagai dasar praktis dalam perancangan kurikulum masih menjadi kendala didalam masyarakat. Hal ini dapat menjadi kajian yang menarik untuk merancang metode dan solusi yang tepat untuk memecahkan setiap masalah sosial di masyarakat (Kamera, 2018). Komunikasi memiliki peran penting bukan hanya sebagai proses namun juga 
sebagai sistem berfikir dalam suatu struktur masyarakat. Eksistensi budaya menjadi salah satu dasari penting dalam perancangan kurikulum MBKM Prodi Ilmu Komunikasi Hindu. Namum sebagai dasar filosofis dari perancangan kurikulum adalah Weda. Weda menjadi rujukan yang sahih dan sangat komprehensif dalam menjelaskan semua komponen kehidupan baik secara skala dan niskala. Weda dirancang dengan sangat detail dan rijit sebagai rujukan dan dasar filosofis dalam perancangan kurikulum MBKM di Prodi Ilmu Komunikasi Hindu.

Terkait dengan perancangan kurikulum MBKM di Prodi Ilmu Komunikasi Hindu, dimana Weda menjadi dasar dalam pembentukan dan berkembangnya Ilmu Komunikasi Hindu, sehingga Ilmu Komunikasi dapat dikaji dengan menggunakan paradigma timur dengan rujukan filosofis adalah Weda. Seperti pada pernyataan berikut ini dimana dalam proses dan perkembangannnya, komunikasi memiliki peran penting dalam setiap aspek kehidupan (Triguna, et.al, 2009). Hal tersebut dikarenakan setiap manusia berproses dalam berkomunikasi. Namun Weda telah memberikan tuntunan-tuntunan berkomunikasi yang baik, sebagai rujukan dalam perancangan kurikulum Ilmu Komunikasi Hindu. Dalam kurikulum harus mampu menjelaskan apa yang menjadi kekuatan dan karakteristik dari Ilmu Komunikasi Hindu.

\section{Weda sebagai Filsosofis Perancangan Kurikulum MBKM}

Membangun kecerdasan emosional yang berdasarkan Weda. Sehingga menjadi sangat penting nantinya, STAH Dharma Nusantara Jakarta sebagai lembaga pendidikan serta khususnya Prodi Ilmu Komunikasi Hindu mampu merancang kurikulum yang secara tuntas mengkaji tentang Weda khususnya yang berkaitan dengan Ilmu Komunikasi Hindu. Sehingga, pelaku komunikasi Hindu mampu berproses dalam berkomunikasi dengan mengimplemetasikan nilai-nilai Hindu yang tertuang dalam Weda. Seperti pada pernyataan berikut ini:

Komunikasi yang berbasis dalam ajaran Hindu. Perilaku orang berkomunikasi yang didasari oleh kecerdasan emosionalnya, namun dalam komunikasi Hindu lebih menekankan pada komunikasi yang berakhir dengan kesuka citaan. Komunikasi yang harus memiliki, kecerdasan secara intelektual, motorik, psikotorik, dll. Prodi harus mampu memberikan pemahaman Veda dengan komplit. Prilaku, pemahaman agama baru menjadi komunikasi Hindu.

Hal senada juga disampaikan oleh informan selanjutnya yaitu I Gusti Made Arya Suta Wirawan, S.Hum., M.Si dalam focus group discussion yang dilaksanakan pada tanggal 4 November 2021, yang menjelaskan tentang bagaimana pradaban Hindu itu sangat Tua sekali, namun masih sangat kuat sampai saat ini. Hal tersebut dikarenakan Hindu memiliki kekuatan dan keunikan-keunikan yang tertuang dengan sangat detail dalam Weda. Sehingga, penting sekali adanya pemahaman tentang Weda sedini mungkin untuk mampu diimplementasikan dalam kehidupan sehari-hari. Seperti pada pernyataan berikut, dimana Weda adalah sumber Ilmu pengetahuan yang sangat kompleks:

Hindu sebagai peradaban yang sangat tua, namun masih eksis dan bertahan dengan segala keunggulannya. Keunikan-keunikan dari agama Hindu dari berbagai belahan dunia. Ketika berbicara tentang Weda yang netabenne adalah kompleks. Sebuah kebanggaan sebagai umat Hindu, patut kita dalami kembali tentang ilmu dan pengetahuan yang terdapat dalam Weda.

Menempatkan Weda sebagai sumber dan dasar filosofis Perancangan kurikulum MBKM Ilmu Komunikasi Hindu, sangat penting memahami paradigma yang akan digunakan untuk mengkaji hal tersebut. Dimana rujukan-rujukan dalam Weda selalu menekankan kepada pembebasan. Ini yang menjadi kekuatan dalam Kurikulum Ilmu Komunikasi Hindu nantinya. Seperti pada pernyataan berikut ini: Sancarsasra disebut 
dalam ilmu komunikasi Hindu, harus bertumpu pada catur asrama, catur marga agar mencapai kebebasan. Keilmuan apa yang akan dipakai, konstruktivis, kritis atau post positivist sains dan teknologi kegunaan ilmu komunikasi dari lulusan STAH Dharma Nusantara Jakarta. Sehingga dapat dinyatakan bahwa, esensi dan kekuatan kurikulum Ilmu Komunikasi Hindu adalah Weda. Karena Weda sudah menjelaskan secara detail semua komponen-komponen yang harus ada dalam memahami Ilmu Komunikasi Hindu. Seperti pada pernyataan I Gusti Made Arya Suta Wirawan dalam focus group discussion yang dilaksanakan pada tanggal 4 November 2021, berikut ini: Jadi dalam berbicara dibidang kurikulum. berbicara tentang weda, seni berbicara, logika, mimamsa, seni dan yoga. Entah bagaimana seseorang memiliki cemistry. Sadharanikaran, sebagai model komunikasi.

Berkembangnya Ilmu Komunikasi tidak bisa dilepaskan dari perkembangan keilmuan yang ada di India yang merujuk pada Weda. Perkembangan Ilmu Komunikasi dimulai dari lahirnya model-model ilmu komunikasi Hindu yang diciptakan oleh seorang Dr. Nirmala Mani Adhikary dari Kathmandu University, Nepal. Dimana model-model Ilmu Komunikasi yang sudah dihasilkan adalah Sadharanikaran Model of Communication (2003, diperbaharui 2010), hingga Bhatta-Mimamsa Model of Communication (2012). Sehingga berdasarkan perkembangan ilmu komunikasi Hindu tersebut, maka model Sadharanikaran ini merupakan salah satu upaya untuk mengikuti perkembangan ilmu komunikasi barat. Walaupaun secara keilmuan dan secara filosofisnya, Weda sudah jauh lebih dulu mengemukakan tentang esensi ilmu komunikasi secara detail (Pillai, 1971).

Esensi dalam pengembagan kurikulum Ilmu Komunikasi Hindu ada pada Weda. Dimana dalam Weda juga menjelaskan bahwa karakteristik Ilmu Komunikasi Hindu adalah pada proses komunikasinya yang tidak hanya terfokus pada manusia namun juga pada alam dan Tuhan Yang Maha Esa. Ini yang menandakan bahwa proses komunikasi tersebut tidak hanya terjadi secara vertikal, namun juga horizontal bahkan supranatural. Pencapaian dalam proses komunikasi Hindu adalah pada penyatuan rasa yang sama yaitu harmonisasi. Sehingga dapat dikatakan bahwa harmonisasi sebagai tujuan dalam perancangan kurikulum Ilmu Komunikasi Hindu. Membangun pemahaman tentang Weda apalagi tentang harmonisasi dalam proses komunikasi yang merujuk pada Weda, tentu saja bukan hal yang mudah dan dapat dipahami secara instan, namun perlu upaya bersamasama seluruh komponen lembaga pendidikan dari masa kanak-kanak hingga masa dewasa. Upaya untuk membangun pemahaman Weda harus tersistem dalam sistem pendidikan formal dan nor formal sehingga apapun keadaannya, setiap umat akan mampu mengimplementasikan Weda secara arif dan bijaksana.

\section{Harmonisasi Sebagai Tujuan Perancangan Kurikulum MBKM}

Pada dasarnya dalam komunikasi Hindu, tentang rasa itu sifatnya spiritual. Rasa yang timbul secara spiritual. Landasan utama dan akhirnya adalah spiritual. yang kedua model komunikasi sadharanikaran sebagai salah satu model dari reaksi Prof Adikari tentang padupadan antara komunikasi Hindu dan komunikasi Barat. I Gusti Made Arya Suta Wirawan, S.Hum., M.Si dalam focus group discussion yang dilaksanakan pada tanggal 4 November 2021, memaparkan bagaimana Weda juga menjelaskan tentang Harmonisasi sebagai tujuan dalam komunikasi Hindu. Seperti pada pernyataan berikut ini:

Tri Hitakarana bagaimana kita tidak hanya berkomunikasi dengan manusia dan alam. Hindu memiliki keunikan dibanding dengan agama yang lain. Kita fokus pada penciptaan keharmonisan. Namun feedback dari alam yang merupakan salah satu tujuan dari komunikasi. Stah DN Jakarta bisa mengembangkan satu model komunikasi yang demikian. Tentu bagaimana kemudian dikonstruk secara detail, yang kemudian memunculkan ide untuk bersama-sama menghasilkan strategi yang tepat. 
Berdasarkan pendapat yang disampaikan oleh I Gusti Made Arya Suta Wirawan, S.Hum., M.Si dalam focus group discussion yang dilaksanakan pada tanggal 4 November 2021, memaparkan tentang esensi dalam ilmu komunikasi Hindu yaitu: Visi dalam komunikasi Hindu adalah Satya, Jnana dan Ananda. Dimana sebagai dasar dalam proses komunikasi Hindu. Dimana proses komunikasi harus mengandung unsur Pengalaman bersama, mencapai rasa kesuka-citaan bersama. Hal menarik juga disampaikan oleh Dr. Wayan Catra Yasa, yang menjelaskan tentang: Antisipasi dari gejolak sosial, ilmu komunikasi dalam prodi ini. Latar belakang pengetahuan yang berbeda dapat membangun satu kolaborasi untuk menghasilkan pemikiran yang baru dan menjawab tantangan di era sekarang. Satya, Jnana dan Anandam adalah visi atau tujuan akhir dari model komunikasi Hindu ini.

Esensi harmonisasi dalam keilmuan komunikasi Hindu yang berbasis pada Weda juga menjelaskan bagaimana proses penyatuan rasa dalam pencapaian kebebasan diri yaitu Moksa. Esensi ilmu komunikasi Hindu tidak hanya bermuara pada Karma saja sebagai tindakan/prilaku yang dihasilkan dalam proses berkomunikasi, namun sampai pada penyatuan secara supranatural. Itulah esensi Sang Brahman sebagai sumber dan objek karakteristik Ilmu Komunikasi Hindu

\section{Brahman Sebagai Sumber dan Obyek Karakteristik Ilmu Komunikasi Hindu}

Implementasi ilmu komunikasi Hindu ini dalam pengembanagn kurikulum MBKM yang menjadi fokus perancangan di Prodi Ilmu Komunikasi Hindu. Dimana, paradigma kajian keilmuannnya harus ditentukan lebih dulu, agar kajian-kajian pembelajaran dalam kurikulum mampu dikembangkan semaksimal mungkin. Seperti pernyataan berikut:

Ilmu kita itu sesuai dengan kurikulum MBKM. Karena pada dasarnya kalo kita mengkaji melalui paradigma, yang menjadi salah satu sumbangan kepada masyarakat secara langsung. Menciptakan suatu kompetensi yang siap berpartisipasi dalam dunia industri dan masyarakat secara langsung. apakah di susunan kurukulumnya dimasukkan unsur siar, dharmawacana dan lain sebagainya. Harus memuat ilmu dasar yang memuat tentang weda, wicara, tarka, satya, mimamsa, dan yoga. Kerjasama dengan dunia industry. Komunikasi Hindu sebagai sebuah suatu keilmuan kita harus menentukan suatu paradigmanya terlebih dahulu mis : positivis, konstruktivis atau transpormatif. Dengan memilih paradigma konstruktivis atau transpormatif dimana ilmu itu akan dapat memberikan sumbangsih, bisa menggerakan masyarakat bisa mengubah keadaan masyarakat, dengan demikian mata kuliah yang akan di bentuk dalam prodi dapat menciptakan suatu kompetensi yang kelak dapat di implementasikan dalam masyarakat atau dunia industri. Dalam menyusun Prodi Ilmu Komunikasi Hindu hendaknya memuat Ilmu-ilmu dasar : Weda, Wicara, logika, interpretasi, seni serta gerak tubuh dan spiritual , 6 dasar ini yang harus di konstruk dalam mata kuliah ilmu komunikasi yang dipadukan dalam MBKM .

Penjelasan berikut ini yang disampaikan oleh salah satu stakeholder dari STAH Dharma Nusantara Jakarta yaitu Dr. Wayan Catra Yasa dalam focus group discussion yang dilaksanakan pada tanggal 4 November 2021, yang memaparkan dengan apik bahwa proses Komunikasi Hindu yang berbasis ajaran-ajaran Hindu harus mengandung muatan kesukacitaan dan keilkasan yang mendalam. Ini harusnya dipahami betul oleh pelaku komunikasi khususnya yang mengimplementasikan Ilmu Komunikasi Hindu. Seperti pada pemaparan berikut ini: 
Komunikasi Hindu memiliki nilai yang sangat apik, menarik dan kompleks. Komunikasi Hindu yang berbasis dalam ajaran Hindu. Yang perlu kita pahami apa yang akan dikomunikasikan. Perilaku orang yang berkomunikasi menyampaikan komunikasinya dipacu dengan emosi dalam menyampaikan komunikasi karena ada kepentingan didalamnya. Suka cita menjadi esensi yang utama dalam komunikasi senada dengan apa yang disampaikan oleh pak arya. Bagimana komunikasi Hindu disampaikan dengan cara yang baik, ikhlas dan kajian yang ingin dikomunikasikan.

Lebih lanjut lagi, Dr. Wayan Catra Yasa dalam focus group discussion yang dilaksanakan pada tanggal 4 November 2021, juga menjelaskan tentang bagaimana pentingnya membangun kecerdasan emosional yang berdasarkan Weda. Sehingga menjadi sangat penting nantinya, STAH Dharma Nusantara Jakarta sebagai lembaga pendidikan serta khususnya Prodi Ilmu Komunikasi Hindu mampu merancang kurikulum yang secara tuntas mengkaji tentang Weda khususnya yang berkaitan dengan Ilmu Komunikasi Hindu. Sehingga, pelaku komunikasi Hindu mampu berproses dalam berkomunikasi dengan mengimplemetasikan nilai-nilai Hindu yang tertuang dalam Weda. Seperti pada pernyataan berikut ini:

Komunikasi yang berbasis dalam ajaran Hindu. Perilaku orang berkomunikasi yang didasari oleh kecerdasan emosionalnya, namun dalam komunikasi Hindu lebih menekankan pada komunikasi yang berakhir dengan kesuka citaan. Komunikasi yang harus memiliki, kecerdasan secara intelektual, motorik, psikotorik, dll. Prodi harus mampu memberikan pemahaman Veda dengan komplit. Prilaku, pemahaman agama baru menjadi komunikasi Hindu.

Esensi dalam pengembagan kurikulum Ilmu Komunikasi Hindu ada pada Weda. Dimana dalam Weda juga menjelaskan bahwa karakteristik Ilmu Komunikasi Hindu adalah pada proses komunikasinya yang tidak hanya terfokus pada manusia namun juga pada alam dan Tuhan Yang Maha Esa. Ini yang menandakan bahwa proses komunikasi tersebut tidak hanya terjadi secara vertikal, namun juga horizontal bahkan supranatural. Mengacu pada ilmu komunikasi, abhivyanjana proses memproduksi pesan atau encoding. Dalam sadharanikaran, encoding dapat diartikan sebagai penyederhanaan (simplification). Dimana esensi dari proses komunikasi adalah adanya pemahaman bersama melalui sarana dan alat komunikasi sehingga proses komunikasi yang dihasilkan menjadi dinamis, cair dan fleksibel disesuaikan dengan hubungan sosial yang ada (Sutawirawan, 2014).

Komunikasi diambil sebagai proses langkah-demi-langkah, yang hanya demi memudahkan pemahaman, sahridaya-preshaka (pengirim), yang memiliki bhavas (suasana hati atau emosi atau pikiran atau ide) dalam pikiran, adalah inisiator dalam proses tersebut (Adi, 2015). Sang sahridaya (pengirim) harus melewati proses abhivyanjana untuk mengekspresikan bhavas mereka dalam bentuk yang dapat dipahami. Ini adalah sahridaya-prapaka (penerima) dengan siapa bhavas harus dibagi. Dia harus melewati proses rasaswadana (Yasa, 2007). Kritik sastra India telah memberikan tempat tertinggi untuk Rasa. Yang lainnya seperti Alankara, Guna, Riti, Vrtti dan Parvrtti dll menemukan tempatnya di kavya sejauh itu berguna untuk Rasa. Itulah alasan mengapa hanya para penyair yang mencapai kesempurnaan dalam menggambarkan Rasa diberikan tempat yang sangat tinggi di India. Valmiki, Vyasa, Kalidasa (72) dan Bhâva bhuti adalah contoh nyata untuk kesempurnaan tersebut. Dikatakan dalam pujian penyair seperti itu.

Pada proses komunikasi abhivyanjana terdiri dari empat tahap yang didasari pada filosofis Hindu dan falsafah Weda (Suhardi, 2018). Keempat tahapan bahasa (Shabda atau Vak) yang melewati: para, pashyanti, madhyama serta vaikhari. Dalam hal ini, bhava dapat dirasakan secara eksternal hingga sampai terjadi vaikhari. Proses kerja Vakyapadiya 
dalam ilmu komunikasi Hindu adalah bagaimana kata-kata diproduksi oleh manusia dalam pikiran sebagai proses konstruksi makna sebelum diucapkan dalam bentuk verbal yang akan menjadi pemahaman bersama yang bermuara pada kesuka citaan. Dalam proses komunikasi Hindu dimana rasa dan karma juga bekerja sebagai sebagai dasar dalam mencapai tujuan komunikasi.

Sebagai kompedium keilmuan komunikasi Hindu, eksistensi budaya menjadi salah satu dasar penting dalam perancangan kurikulum MBKM Prodi Ilmu Komunikasi Hindu. Namum sebagai dasar filosofis dari perancangan kurikulum adalah Weda. Weda menjadi rujukan yang sahih dan sangat komprehensif dalam menjelaskan semua komponen kehidupan baik secara skala dan niskala. Weda dirancang dengan sangat detail dan rijit sebagai rujukan dan dasar filosofis dalam perancangan kurikulum MBKM di Prodi Ilmu Komunikasi Hindu. Seperti pada gambar berikut ini yang diolah dari hasil penelitian, bagaimana pada bagan perancangan kurikulum MBKM berbasis budaya harus memiliki komponen-komponen seperti eksistensi budaya sebagai dasar dalam perancangan kurikulum Merdeka Belajar Kampus Merdeka di prodi Ilmu Komunikasi Hindu, serta menempatkan Weda sebagai rujukan filosofis dalam pengembangan kurikulum Ilmu Komunikasi Hindu, adanya harmonisasi sebagai tujuan dalam pencapaian kurikulum Ilmu Komunikasi Hindu, serta Brahman sebagai sumber dan objek dalam menguatkan karakteristik Ilmu Komunikasi Hindu.

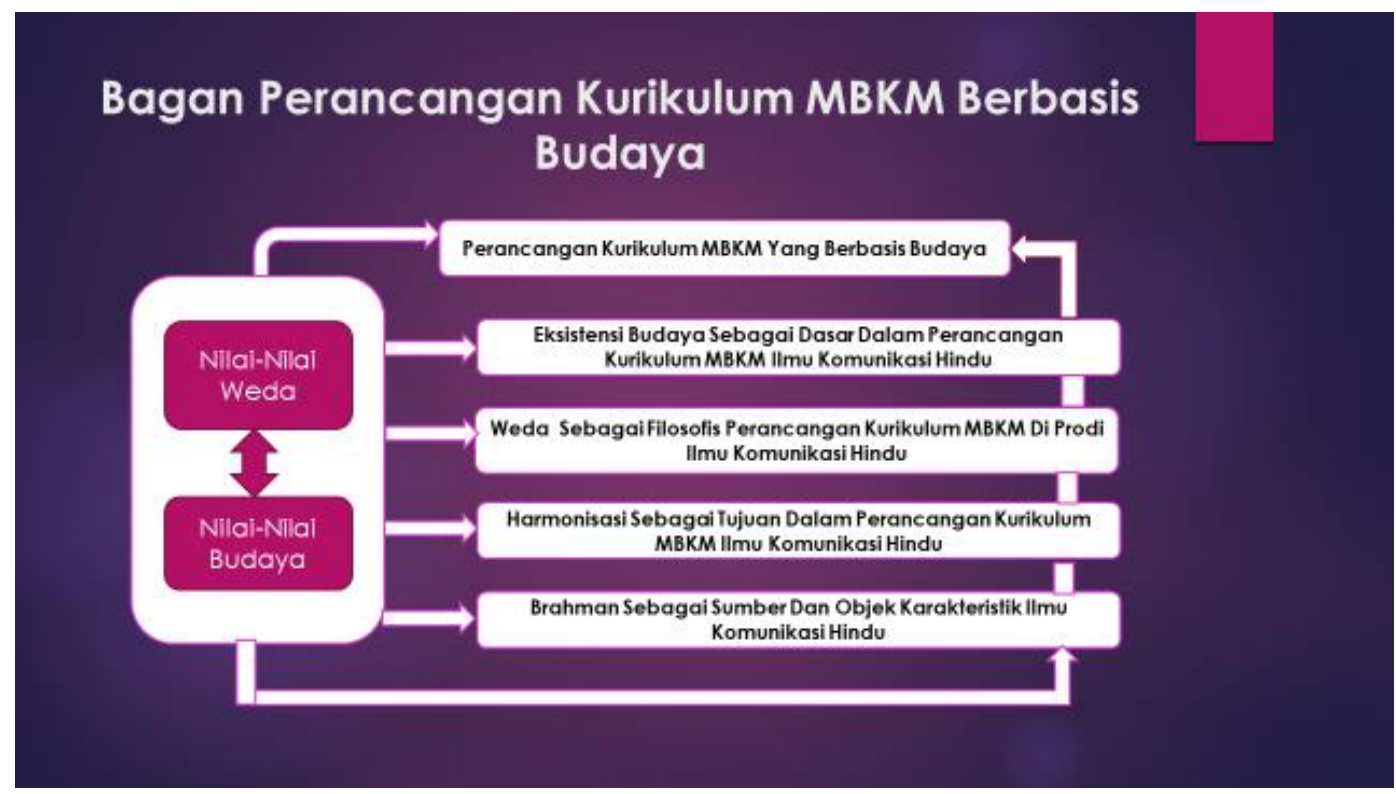

Gambar 1. Bagan Perancangan Kurikulum MBKM Berbasis Budaya

(Sumber: Diolah dari Hasil Penelitian, 2021)

Terkait dengan perancangan kurikulum MBKM di Prodi Ilmu Komunikasi Hindu, dimana Weda menjadi dasar dalam pembentukan dan berkembangnya Ilmu Komunikasi Hindu, sehingga Ilmu Komunikasi dapat dikaji dengan menggunakan paradigma timur dengan rujukan filosofis adalah Weda. Dimana dalam konteks sejarah Ilmu komunikasi Hindu perlu dipahami melalui tiga perspektif sebagai berikut: 1) Sistem Parampara atau Guru Sisya, 2) Tradisi oral yang menjadi alat perekam pemahaman Weda, yang kemudian dihimpun kembali dalam bentuk tulisan, 3) Seni Drama Kejelasan pondasi keilmuannya menjadi sangat penting seperti epistemelogi, ontologi dan aksiologi. Konteks seni drama diatas panggung menjadi sebuah analogy dari proses komunikasi. Gandharwa Weda merupakan pondasi keilmuan yang menjadi sebuah pendekatan yang menjelaskan bahwa komunikasi tidak hanya soal oral namun juga tentang hermenetika budaya dan bahasa. 
Satu pendekatan yang menarik, sehingga dapat menjadi salah satu acuan dalam inovasi dan pedoman dalam komunikasi Hindu. 4) Secara literal dimunculkan dalam Arthasastra, Dalam komunikasi, mengandung, kebenaran, pengetahuan dan kesukacitaan. Kesepahaman baru menjadi sebuah pemikiran baru. Visi dari Ilmu Komunikasi Hindu harus memuat pada tiga unsur tersebut. Dimana dalam Arthasatra tidak hanya memuat tentang seni berpolitik saja, namun dalam proses komunikasi atau menyampaikan pesan harus menimbulkan suatu pengetahuan dan bagaimana cara menyampaikan dan akhirnya menimbulkan ketertarikan.

\section{Simpulan}

Nilai-nilai budaya dan nilai-nilai Hindu menjadi dasar filosofis dalam perancangan kurikulum Merdeka Belajar Kampus Merdeka dan Weda menjadi rujukan filosofis dalam mengembangkan teori keilmuan komunikasi Hindu berbasis budaya, kearifan lokal dan digital. Sebagai kompedium keilmuan komunikasi Hindu yang dikemas dalam perancangan kurikulum MBKM berbasis budaya menghasilkan empat kategorisasi sebagai temuan dalam penelitian ini yaitu; eksistensi budaya sebagai dasar dalam perancangan kurikulum MBKM Ilmu Komunikasi Hindu, Weda sebagai filosofis perancangan kurikulum MBKM di Prodi Ilmu Komunikasi Hindu, harmonisasi sebagai tujuan dalam perancangan kurikulum MBKM Ilmu Komunikasi Hindu, dan Brahman sebagai sumber dan objek karakteristik Ilmu Komunikasi Hindu.

\section{Daftar Pustaka}

Adi, S. P. I. M. (2015). Laukika dan Waidika Sebagai Konsep Komunikasi Hindu Dalam Epistimologi Sabda Pramana. PASUPATI Jurnal Ilmiah Kajian Hindu Dan Humaniora, 3(2), 77-92.

Baharuddin, M. R. (2021). Adaptasi Kurikulum Merdeka Belajar Kampus Merdeka (Fokus: Model MBKM Program Studi). Urnal Studi Guru Dan Pembelajaran, 4(1), 195-205.

Junaedi, A. (2020). Buku Panduan Penyusunan Kurikulum Pendidikan Tinggi Di Era Industri 4.0 Untuk Mendukung Merdeka Belajar-Kampus Merdeka (I). Jakarta: Direktorat Pembelajaran dan Kemahasiswaan, Direktorat Jenderal Pendidikan Tinggi, Kementerian Pendidikan dan Kebudayaan.

Kamera, U. (2018). Post-Truth Hoax dan Religiusitas di Media Sosial. Ilmu Aqidah Dan Studi Keagamaan, 6(2), 283-302.

Penyusun, T. (2020). Profil Pelajar Pancasila. Jakarta: Pusat Kurikulum dan Perbukuan Kementerian Pendidikan dan Kebudayaan.

Pillai, R. (1971). The Vakyapadia (Studies The Vakyapadia Vol. I) (I). Delhi: Sri Jainendra Press.

Salim, A. (2001). Teori dan Paradigma Penelitian Sosial (I). Yogyakarta: Tiara Wacana.

Sudiani, Ni Nyoman, Sukirno Hadi Raharjo, dan U. S. (2020). Pendidikan Agama Hindu (II). Tangerang Selatan: Universitas Terbuka.

Sugiyono. (2006). Metode Penelitian Kuantitatif, Kualitatif dan $R \&$ D. Bandung: Alfabeta.

Suhardi, U. (2018). Etika Komunikasi dalam Veda (Tinjauan Fenomenologi pada Era Globalisasi). PASUPATI Jurnal Ilmiah Kajian Hindu Dan Humaniora, 5(1), 6180 .

Suryaman, M. (2020). Orientasi Pengembangan Kurikulum Merdeka Belajar. In Pengembangan Kurikulum Merdeka Belajar (pp. 13-28). Yogyakarta: Universitas Negeri Yogyakarta. 
Sutawirawan, I. G. M. A. (2014). Shadaranikarana Sebagai Model Komunikasi Dalam Hindu. PASUPATI Jurnal Ilmiah Kajian Hindu Dan Humaniora, I(1).

Suwandi, S. (2020). Pengembangan Kurikulum Program Studi Pendidikan Bahasa (dan Sastra) Indonesia yang Responsif terhadap Kebijakan Merdeka Belajar-Kampus Merdeka dan Kebutuhan Pembelajaran Abad ke-21. In Pengembangan Kurikulum Merdeka Belajar (pp. 1-12). Surakarta: Universitas Sebelas Maret.

Titib, I. M. (1997). Pendidikan Karakter dalam perspektif Agama Hindu (I). Surabaya: Paramita.

Triguna, IBG Y. et. a. (2009). Pedoman Penyiaran Agama Hindu. Jakarta: Ditjen Bimas Hindu Kemenag RI.

Yasa, I. W. S. (2007). Teori Rasa: Memahami Taksu, Ekspresi, dan Metodenya. (I. W. Teguh, Ed.) (I). Denpasar: Program Magister Universitas Hindu Indonesia Bekerjasama dengan Penerbit Widya Dharma. 